\title{
Technology, Governance, and a Sustainability Model for Small and Medium-Sized Towns in Europe
}

\author{
Maria José Sousa ${ }^{1,2, *(\mathbb{D}}$, Pere Mercadé Melé ${ }^{3}\left[\right.$ and Jesús Molina Gómez ${ }^{4}(\mathbb{C}$ \\ 1 Department of Political Science and Public Policies, Instituto Universitário de Lisboa, \\ 1649-026 Lisboa, Portugal \\ 2 CIEO, Algarve University, 8005-139 Faro, Portugal \\ 3 Department of Statistics and Econometrics, University of Malaga, Campus el Ejido s/n, 29071, Malaga, Spain; \\ pmercade@uma.es \\ 4 Department of Economics and Business, University of Malaga, Campus el Ejido s/n, 29071, Malaga, Spain; \\ jmolinag@uma.es \\ * Correspondence: maria.jose.sousa@ISCTE-IUL.pt
}

Received: 16 December 2019; Accepted: 21 January 2020; Published: 24 January 2020

\begin{abstract}
New and cutting-edge technologies causing deep changes in societies, playing the role of game modifiers, and having a significant impact on global markets in small and medium-sized towns in Europe (SMSTEs) are the focus of this research. In this context, an analysis was carried out to identify the main dimensions of a model for promoting innovation in SMSTEs. The literature review on the main dimensions boosting the innovation in SMSTEs and the methodological approach was the application of a survey directed to experts on this issue. The findings from the literature review reflect that technologies, governance, and sustainability dimensions are enablers of SMSTEs' innovation, and based on the results of the survey, a model was implemented to boost innovation, being this the major add-on of this research.
\end{abstract}

Keywords: SMSTEs; innovation; technologies; digital; governance; sustainability

\section{Introduction}

The emergence of new technologies and scientific discoveries is changing the status quo and people's lifestyle and work [1], as well as boosting the innovation in regions and towns [2] by the introduction of local innovation policies or through the potential of innovation of the companies creating new products and services as well as new business models-those vectors can be named as game changers.

Game changers, in the context of this paper, are the technologies that allow the market transformation and change the ways of communication, collaboration, education, training, and innovation [3]. Their potential moves in new ways of thinking and acting, transforming society, towns, organizations, and individuals [4].

Technologies such as smartphones and tablets for mobile applications and cloud-based technologies have contributed to a myriad of technological advancements, but to keep companies competitive it is necessary to anticipate the most significant technology trends.

In all economic sectors, information has become a distinctive factor of competitiveness, and intellectual capital presents itself as a primary factor of competitiveness as it depends on powering of the information process. Therefore, a company based on knowledge and using emerging technologies leads to the decision-making process and becomes adapted to the real networks of communication and globalization. It enables an easier learning process and allows the re-use of 
knowledge, measurement of better professional performance of the workers, a greater use of the available parts, and an increase of the efficiency in the decision-making process.

Companies located in SMSTEs [5-7] perceive the competitive advantages that technologies can bring to implementation of their strategies and redefining of their business or completely innovative business creation in regions where the conditions are more favourable, namely, regarding taxes and funding access.

Disruptive technologies are redefining the SMEs in SMSTEs and business landscape through companies that are equipped with state-of-the-art technologies [8] enabling 3D printing, prototyping, as well as innovative applications of new product materials, once technologies redefine the creation of technology start-ups and co-working spaces, where technologies such as cloud computing, big data, artificial intelligence, and the Internet of Things assume the role to trigger new business.

In the case of SMEs, representing 99\% of the total companies in Europe, generally, the needs for transformation are urgent and simply innovating and applying technologies create a new trigger for changes in social, political, and organizational levels. In the context of this study, as SMEs are in higher numbers and are considered a market driver, their development and competitive capacity directly influence the development and sustainability of the SMSTEs. Associated with the game changer technology, two other dimensions are critical to the development of SMSTEs: governance and sustainability. All of these dimensions are the trigger that enables the evolution of SMSTEs for a transformation in smart cities.

Smart cities are not only focused on technology but also focus on creating conditions for a better quality of life of the citizens, to create conditions for better mobility, for a greener lifestyle, and more green companies, with impact on investment on renewal energies, and on resource sustainability, i.e., natural resources, but also financial and technological resources.

This research identifies the leading technologies and proposes a model for SMSTE growth in the global economy. Moreover, this study is focused not only on the SMEs' performance but also on the researchers that took the option to design a model with the assistance of several experts capable of promoting the development of the SMSTEs.

This study is exploratory and will be focussed on the crucial dimensions of a model to promote innovation in SMSTEs, targeting policymakers, politicians, company managers, citizens, and researchers. This is the main innovation on this research: not only the model proposal, but the model impact in giving a new perspective for policymakers in terms of a policy definition, for SMEs and other company managers, as a guideline to reformulate their strategies, and for citizens, regarding their expectation evolution potentialities from their small or medium town to a smart city, more digital, with more mobility options and on that is greener and sustainable.

For a better understanding of the analysis, the article is organized as follows: first, the literature review, followed by the methods applied in the research process, then the model proposal, and finally a discussion and conclusions.

\section{Literature Review}

\subsection{Literature Review Methodology}

The methodological approach procedure on the literature review was qualitative, and the primary main technique for data to collection and analyse data was the analysis content of the papers on technologies to improve innovation in SMSTEs. For this paper, a bibliometric search and analysis was performed executed using through b-on, a which is a research resource which allowing allows access to thousands of scientific texts publications included in sites such as from Elsevier, ISI, Sage, and Springer, among others.

In the beginning of the segmentation, the terminology "Small and Medium Size Towns and Innovation" was used as a first filter and a time horizon of research for the last thirty years (1990-2020), obtaining a total of 15,056 publications. Subsequently, new segmentations criteria of exclusion were 
used, limiting the number of publications: independent research of peer-reviewed scientific articles in academic publications, the theme was "technology", and European geography (30 articles).

The analysis goal was to extract and analyse the article's title, methodology, and findings to extract expressions related to small and medium-sized towns associated with technology, governance, and sustainability.

Moreover, information technologies (IT) have generated innovation [9] for SMSTEs and companies. IT has also created conditions for a better position of companies in the international markets [10] through digitalization and digital trade platforms, as well as their participation in international networks and digital value chains, but has also created opportunities to advance in the utilization of new types of resources and materials, regarding the sustainability of the environment and life in those types of SMSTEs. Despite all the economic and political challenges, SMSTEs have the technology to continue to move forward and also to influence the macroeconomic factors of European countries having a significant impact on global markets.

\subsection{Disruptive Technologies to Potentiate Innovation in SMSTEs}

In this section, an overview is carried out of the leading technologies that emerged from the paper's analysis and which are being adopted across European countries.

Information and communication technologies (ICTs) are the driving force behind the creation of most other game changers [11] including personal computers and systems, application and management software, as well as the Internet and cloud technology. The Internet has been leveraging the creation of Industry 4.0, which encompasses the Internet of Things, Internet of Data, Internet of Services, and Internet of People [12,13]. In this era where big data is a cross-industry phenomenon that is integrated into the day-to-day activities of businesses and individuals, game changers play the role of the driver and, at the same time, are driven by this phenomenon.

Technological applications are numerous and have revolutionized markets: (a) E-corporate communication: implementation of systems enabling the integration of all areas of the company online. (b) Digital business: the Internet, being a market of millions of users, is a system with numerous advantages in the business world [14]. Some benefits to be derived from the Internet include, for example, disclosing the image of the company and its services to target markets and the market in general, facilitating the creation of a customer base, using its characteristic interactive tools to implement market analysis, and allowing rapid and effective access to information, and more. However, the question of cybersecurity and data privacy has to be considered at a global level.

Moreover, it is necessary to take into account some aspects beyond the markets, such as an analysis of the costs inherent in the process of creating, updating, and maintaining the digital platforms, combining them with the costs of the marketing strategy adopted. (c) Mobile business, the application of mobile technology to the digital business, adds the advantages inherent in mobility [15]. The concept of physical space becomes flexible once this technology allows us to carry out business activities through tools such as smartphones and tablets [16]. (d) Thematic portals allow us to create a user profile to customize the type of information individuals want to view. For example, when accessing a portal, it will be possible to customize it by indicating the themes (finance, economy, business, and others) of interest to you; from that moment on, you will only access this type of information. (e) Simultaneous engineering: the realization of the various phases of a project is done interactively, involving professionals from different specialties from the beginning to the end. Workgroup computing tools are used, which allow cooperative work between the various elements of the project team (project engineers, process engineers, quality elements, marketing, production, among others) to increase the effectiveness and efficiency. (f) Virtual reality is the creation of three-dimensional simulated computer environments that allow real-time interactions. In the business context, virtual reality has multiple applications at the level of the production of simulated situations, such as prototyping, metal alloys, and design, among others. 
The advancement of technology continues to drive economic growth and, in some cases, trigger disruptive changes that transform society and organizations. Technology has made possible the creation of new business models, the redefinition of corporate structures, and definition of the content of the work.

In addition to the information and communication systems already discussed, the following technologies will be explored: the Internet of Things, cloud computing, big data, artificial intelligence, robotics, and mobile technologies, as they are the focus of development and implementation by the European Union in the Digital Transformation Scoreboard 2018.

The Internet of Things is technology that represents a network of applications, and hardware, capable of gathering massive quantities of data, and processing it in order to share the information among the users, using the internet communication protocol [17]. The Internet of Things is changing the manufacturing industry, energy, agriculture, transport, and other industrial sectors of the economy [18]. These technological applications to industry are leading to the emergence of new business opportunities, but also to new risks for business and society as the access to sensitive data is facilitated with the possibility to to control the physical world, including machines and factories [19]. The work processes are also being transformed due to new interactions between people and machines [20].

Cloud Computing allows the possibility for the use of major quantities of data and applications, and access them everywhere, based on the Internet in real-time or on-demand [21]. Big Data is a concept associated to the increasing data volume [21], as the massive use of Internet, social networks, and mobile devices has leaded to facilitate the access tolarge datasets such as images or text. It has increased the need for applications and algorithms that easily allows data analysis, data selection, and data security. This technology allows data capture and interpretation, namely, visualisation of strategic information for companies decision-making process.

Artificial Intelligence and Robotics is the development of computer systems capable of performing tasks that usually require human intelligence [22]. This technology has multiple applications in the industry. Robots with artificial intelligence can perform human tasks [23], are currently applied in different situations, such as in games, computer programs, security systems, devices for recognizing writing and voice, medical diagnostic applications, and telecommunications.

Mobile technologies are massively used, facilitating the communication process and allowing multiple uses through applications conceived to facilitate the day-by-day citizens life. Mobile technologies allows the emergence of new business models, and new working methods. Examples of these technologies include laptops or notebooks (laptops), palmtops, smartphones, GPS devices (global positioning system). These mobile devices allows to take/make and have access to photos, videos, PowerPoint presentations, and messages. Moreover, allows to make payments, check balances and statements, manage the contact list and the calendar in real-time and everywhere. The main opportunities, facilitators, and obstacles to promote innovation through the introduction of this disruptive technology in SMSTEs (Table 1) are related to the (a) opportunities of creating new industries, products and services, redefinition of the processes, data and technological infrastructure, and implementing new work practices; (b) facilitators such as the cloud, increase the connectivity, the use of digital infrastructures, the use of real-time analytics, the maturity of the software industry and also the investments of large IT (Information Technologies) companies; and (c) obstacles related to cybersecurity issues without secure, feasible, and stable solutions; legal aspects, namely, complex legal situations associated with privacy and security; increased investment in digital infrastructure; a lack of interoperability standards; difficulties regarding the investment in new technologies and infrastructures; and the need to devise strategies to mitigate security risks, as systematized in Table 1: 
Table 1. Opportunities, facilitators, and obstacles of technology to promote innovation in SMSTEs.

\begin{tabular}{ccc}
\hline Opportunities & Facilitators & Obstacles \\
\hline $\begin{array}{c}\text { Create new products and services: IoT } \\
\text { will help create and deliver new } \\
\text { products and services at an } \\
\text { unprecedented speed and scale. }\end{array}$ & $\begin{array}{c}\text { Cloud: Increase connectivity and } \\
\text { data availability across the network, } \\
\text { but also the need to create security } \\
\text { and privacy mechanisms. }\end{array}$ & $\begin{array}{c}\text { Security: Data security and } \\
\text { privacy, which are already } \\
\text { growing in importance given the } \\
\text { more significant vulnerabilities to } \\
\text { espionage attacks and data } \\
\text { breaches boosted by increased } \\
\text { connectivity and data sharing. }\end{array}$ \\
\hline $\begin{array}{c}\text { Creating and destroying industries: IoT } \\
\text { brings new opportunities for the } \\
\text { generation of new economic } \\
\text { opportunities and industries. }\end{array}$ & $\begin{array}{c}\text { Ubiquitous connectivity: robust } \\
\text { infrastructures, such as ubiquitous } \\
\text { broadband connectivity and sensors. }\end{array}$ & $\begin{array}{c}\text { Legal aspects: complex legal } \\
\text { situations with privacy and } \\
\text { security and increased investment } \\
\text { in digital infrastructure. }\end{array}$ \\
\hline $\begin{array}{c}\text { Redefine processes, data, } \\
\text { and infrastructure: IoT enables us to } \\
\text { define and create new digital processes } \\
\text { and new infrastructures to manage the } \\
\text { vast amount of data that need to } \\
\text { be addressed. }\end{array}$ & $\begin{array}{c}\text { Sensors: digital infrastructure with } \\
\text { embedded sensors. }\end{array}$ & $\begin{array}{c}\text { Interoperability: lack of } \\
\text { interoperability standards. }\end{array}$ \\
\hline $\begin{array}{c}\text { Transform the way work is done: IoT } \\
\text { will lead to the redefinition of new types } \\
\text { of jobs to be created and will }\end{array}$ & $\begin{array}{c}\text { Real-time analytics: real-time data } \\
\text { analysis to anticipate equipment } \\
\text { failures and respond more quickly } \\
\text { to critical situations. }\end{array}$ & $\begin{array}{c}\text { Privacy: risk of violating the } \\
\text { privacy of citizens and their data. }\end{array}$ \\
\hline
\end{tabular}

\subsection{The governance of SMSTES}

Governance has become a priority for policymakers, financial institutions, investors, companies, and academics, framed by the principles: (1) transparency, (2) accountability, (3) responsibility, and (4) fairness. Governance is crucial as per the society perspective and political environment in order to improve the public confidence (namely, trust, ethics, and moral values), even when the resources are limited to meet the stakeholder's expectations (citizens, government; service providers, and the corporate sector).

With respect to analysis at a micro level, corporate governance [23] is the application of best management practices, compliance of law in true letter and spirit, and adherence to ethical standards for effective management and distribution of wealth, as well as the discharge of social responsibility for the sustainable development of all stakeholders. It is the conduct of business following the shareholders' desires (maximizing wealth) while confirming the basic rules of the society embodied in the law and local customs.

Corporate governance procedures determine every aspect of the role for company management and try to keep in balance and develop control mechanisms in order to increase both shareholder value and the satisfaction of others. In other words, corporate governance is concerned with creating a balance between the economic and social goals of a company, including such aspects as the efficient use of resources, accountability in the use of its power, and the corporate behaviour in its social environment [24].

The literature has shown that corporate governance matters significantly to a company's performance, market value, and credibility of stakeholders [25]. Therefore, companies need to improve their strategy and its implementation framed by the governance principles.

These principles need to be integrated at a political level—in a macro analysis (analysing the variables of the political context)—when regarding the promotion of the SMSTEs and changing them 
to become more competitive and innovative, as governance is the new mainstream that has assumed a more relevant role since the financial crises, imposing principles of trust, transparency, confidence, and moral values. On the one hand, the goal is to allow better access to external finance and lower costs of capital and interest rates on loans to improve performance, and consequently, sustainability. On the other hand, the goal is to increase the value of the SMSTEs to reduce the risk of financial crises and scandals, achieving sustainable development of all stakeholders in the community.

The main governance research concepts identified in the literature are as follows: individual values, organizational vectors, and mixed individual and organizational dimensions (Table 2).

Table 2. Governance research concepts.

\begin{tabular}{ccc}
\hline Individual Values & Organizational Vectors & Mixed Individual and Organizational Dimensions \\
\hline Honesty & CSR & Employability \\
\hline Integrity & Sustainability & Continuous performance improvement \\
\hline Respect & Governing & Smart Governance \\
\hline Trust & Corporate Governance & Compliance of law \\
\hline Accountability & Corruption Risk & Shareholders \\
\hline Justice & Committees & Stakeholders \\
\hline Equity & Auditing & Legal \\
\hline Transparency & Reporting and Communication & Leadership \\
\hline Excellence & Managers' Compensation Plans & Culture \\
\hline Ethics & $\begin{array}{c}\text { Corporate Policy on } \\
\text { Environmental Protection }\end{array}$ & Quality \\
\hline
\end{tabular}

Source: Author's own elaboration.

\subsection{A sustainability framework for SMSTES}

Sustainability means that one effect taken in an action in the present time will have consequences in the future [26], regarding several fields, namely, financial, environment, climate, natural resources, and others. Regarding the context of SMSTEs, one of the drivers for their development is resources. If resources are used until they run out in the present, then they are no longer available in the future, and the sustainability of the companies that use that resource in their activity is compromised.

Sustainability requires that resources to be used are those possible to be regenerated, taking into account the capacity of the ecosystem [27]. A good practice is made by the paper industry, with the policy of replanting trees to replace those used in their activity. As the companies are part of a community and in most cases of an SMSTE, a more comprehensive social and economic system (Hart, 1997), it is crucial to consider all the consequences of the current actions, not only to achieve higher efficiency but also to create a context of future sustainability [28], in the sense of sustainable development.

According to [26], four aspects of sustainability need to be considered for analysis as they are critical dimensions of sustainability: (1) societal influence, which we define as a measure of the impact that society has upon the corporation in terms of the social contract and stakeholder influence; (2) environmental impact, which we define as the effect of the actions of the corporation upon its geophysical environment; (3) organizational culture, which we define as the relationship between the corporation and its internal stakeholders, particularly employees, and all aspects of that relationship; and (4) finance, which we define in terms of an adequate return for the level of risk undertaken.

Moreover, it is essential to consider a long-term approach to create sustainability [29] for the future of SMTSEs and also for the companies and to achieve sustainable development, focusing on: (a) an integrated approach as both are fundamental for each other's development; (b) creating national and international partnerships for sustainability, being part of innovation and knowledge 
networks and participating in national and international projects; and (c) creating and implementing sustainability monitoring and reporting tools to measure the process and the success of the initiatives and projects implemented.

\subsection{Smart Cities: the Effective Future of SMSTEs}

A smart city is the one that manages its assets efficiently, investing in innovation to promote sustainable urban development. To be considered a smart city, models of governance, strategy for sustainability, and investment in technologies [30] to promote social, economic, and political development is crucial.

The literature presents several definitions for smart cities, being the most cited the following ones (Table 3):

Table 3. Definitions of a Smart City.

Reference
Definition
"A city that monitors and integrates conditions of all of its critical
infrastructures including roads, bridges, tunnels, rails/subways, airports,
seaports, communications, water, power, even major buildings; can
better optimize its resources, plan its preventive maintenance activities,
and monitor security aspects while maximizing services to its citizens
$\ldots$.. systems and structures will monitor their own conditions and carry
out self-repair as "needed"”

"Connecting the physical infrastructure, the IT infrastructure, the social intelligence of the city"

"We believe a city to be smart when investments in human and social capital and traditional (transport) and modern (information and Caragliu et al. (2011) communications technology ICT) communication infrastructure fuel sustainable economic growth and a high quality of life, with a wise management of natural resources through participatory governance"

"A smart city is a city seeking to address public issues via ICT-based

(Manville et al. (2014) solutions on the basis of a multi-stakeholder, municipally based partnership"

"A smart city is a city performing well in a forward-looking way in Giffinger et al. (2007) these six characteristics, built on the 'smart combination of endowments and activities of self-decisive, independent, and aware citizens"

"A smart city is a well-defined geographical area, in which high technologies such as ICT, logistic, energy production, and so on,

Dameri (2013) cooperate to create benefits for citizens in terms of well-being, inclusion and participation, environmental quality, and intelligent development; it is governed by a well-defined pool of subjects able to state the rules and policy for the city government and development"

Source: Camero and Alba 2019 [31].

From a more practical perspective, The International Data Corporation defines a smart city as a city that uses digital technologies to develop and make more efficient and greener areas, namely: energy; environment; governance; mobility; and buildings and services to improve the quality of life of the citizens and creating conditions for sustainable economic growth.

Analysing the dimensions of a smart city, we can focus on the strategy of SMSTEs in order to consider the following vectors:

(a) Governance: focusing on the definition of a model to manage the city considering both private and public actors and all the economic and social stakeholders. It is needed to develop administrative simplification and modernization, promoting open and interactive governance. The contemporary 
models of governance are framed by the stakeholder's theory focusing on citizens' participation in all the processes of the development and progress of the city.

(b) Technology: developing and implementing systems integrating artificial intelligence, robotics, The Internet of Things, and big data. The promotion of digitization can contribute to spreading trade by giving companies new business opportunities, access to a higher number of markets, and placing more products in these markets. Technology can be a solution to improve the competitiveness of SMSTEs as it is a driver of digital trade, flattening barriers that do not allow companies with fewer resources to meet their potential or even to develop themselves and be more competitive.

(c) Energy, environment, and buildings: to promote energy efficiency and the use of renewable energies and to develop sustainable solutions for the construction and rehabilitation of buildings. Defining a strategy to reduce the carbon footprint and the impact of human actions on territories and to contribute to climate change. Also, it is essential to include intelligent systems of water and waste.

(d) Mobility: implementing efficient mobility systems through the use of eco-efficient vehicles and the development of intelligent mobility solutions.

(e) Quality of life: using innovation as a strategy to accomplish social needs in areas such as health, education, tourism, and others, assuring a more inclusive and equitable society.

In this context, the SMSTEs have to focus their strategy to accomplish the level of a smart city in order to achieve a good governance status and sustainability in the future. Technology is a driver for that achievement, but also the focus on social innovation and the citizen's needs and participation in all the processes, i.e., criteria to achieve an open governance model.

\section{Empirical Methodological Approach}

\subsection{Methods}

This is an exploratory quantitative study using a questionnaire as the primary source of data collection, applied to 34 academics and experts. The questionnaire was based on the theoretical framework, assuming the transformation of SMSTEs into smart cities, being the main dimensions the technology, governance, and sustainability, as discussed above in the literature review.

The questionnaire has two sections: the first has four demographic questions (country, type of organization, job position, academic degree) and a scale of 12 statements (about technology, governance, and sustainability). The second section of the questionnaire is a scale of seven choices for the evaluation of all 12 statements, ranging from "disagree completely" (1) to "agree" (7). The respondents represent 34 academics and experts in the Innovation and Public Policies field.

The questionnaire was validated according to the criterion content validation, listing all the items to measure that were found in the literature as well as verifying if the questionnaire addresses all of them. The questions were elaborated based on the team's prior experience and questionnaires published in the scientific literature. [32]. This process allowed us to ensure that every item corresponded to the needed measurement. After that process, the questionnaire was also validated by the criterion internal consistency, which was assessed by the inter-item correlations, which indicated whether the items fit together theoretically—the validation was calculated using Cronbach's alpha $(\alpha)$.

A sample was surveyed with a semi structured questionnaire and by convenience. In this sense, it was gathered the opinion of a group of experts, using a Delphi analysis. The convenience sampling is valid when there are difficulties to obtain a large sample. The online questionnaire was applied to 80 experts and that resulted in 34 valid questionnaires (42.5\% of response rate), a percentage suitable to perform an exploratory study, as given recent experience with response rates, this is an acceptable response rate, besides the high number of missing responses, which is a consequence of the short timeline for the data collection procedure. There are some limitations because the sample was composed of respondents of a particular type and could not represent all the different perspectives. 
The decision about the respondents was based on their positions in order to capture the plurality of opinions on the topics of innovation of public policies.

\subsection{Data Analysis and Results}

\subsubsection{Profile of the Respondents}

The following tables represent the profile of the respondents regarding their positions, academic degree, type of organization, and country of origin. Regarding the respondent's position, Table 4 shows that they are experts, researchers, institutional representatives, or policymakers:

Table 4. Job position of the respondents.

\begin{tabular}{ccc}
\hline Job Position & N & \% \\
\hline Experts & 8 & $24 \%$ \\
\hline Researchers & 10 & $29 \%$ \\
\hline Institutional Representative & 9 & $26 \%$ \\
\hline Policymaker & 7 & $21 \%$ \\
\hline Total & $\mathbf{3 4}$ & $\mathbf{1 0 0 \%}$ \\
\hline
\end{tabular}

Source: Author's own elaboration.

The positions of the respondents are ordered as follows: researchers $(n=10)$, institutional representatives $(n=9)$, experts $(n=8)$, and policymakers $(n=7)$.

The experts and researchers that participated in data collection represent 3 different countries (Portugal, Ireland, and Italy) (Table 5).

Table 5. Background information on the respondents of the questionnaire.

\begin{tabular}{ccc}
\hline Country & $\mathbf{N}$ & $\mathbf{\%}$ \\
\hline Portugal & 15 & $44 \%$ \\
Ireland & 4 & $12 \%$ \\
Italy & 7 & $21 \%$ \\
Spain & 8 & $24 \%$ \\
Total & $\mathbf{3 4}$ & $\mathbf{1 0 0} \%$ \\
\hline
\end{tabular}

Source: Author's own elaboration.

The types of respondents were primarily from Portugal $(n=15)$, Spain $(n=8)$, Italy $(n=7)$, and Ireland $(n=4)$.

Table 6 presents the academic degree of the respondents:

Table 6. Academic degree of the respondents.

\begin{tabular}{ccc}
\hline Academic Degree & N & \% \\
\hline Doctorate & 8 & $24 \%$ \\
Master & 16 & $47 \%$ \\
Licentiate & 10 & $29 \%$ \\
Total & 34 & $\mathbf{1 0 0} \%$ \\
\hline
\end{tabular}

Source: Author's own elaboration.

The academic degree of the respondent is ordered as follows: masters $(n=16)$, licentiate $(n=10)$, and doctorate $(\mathrm{n}=8)$.

Regarding the type of organization represented by the respondents, it is possible to observe in Table 7 that they are from universities, research centers, public organizations, and private organizations: 
Table 7. Type of organization of the respondents.

\begin{tabular}{ccc}
\hline Type of Organization & N & \% \\
\hline Universities & 6 & $18 \%$ \\
Research Centers & 4 & $12 \%$ \\
Public Organizations & 21 & $62 \%$ \\
Private Organizations & 3 & $9 \%$ \\
Total & $\mathbf{3 4}$ & $\mathbf{1 0 0 \%}$ \\
\hline
\end{tabular}

Source: Author's own elaboration.

The public organizations are represented by a higher number $(n=21)$, followed by the universities $(n=6)$, the research centers $(n=4)$, and finally, the private organizations $(n=3)$.

\subsubsection{Analysis of the Reliability}

Due to the very small sample, 34 respondents, the statistical analysis had several limitations and was conducted by Cronbach's alpha coefficient to estimate the reliability of the items of the questionnaire. Cronbach's alpha is calculated by correlating the score for each scale item with the total score for each observation and then comparing that to the variance for all individual item scores.

The resulting $\alpha$ coefficient of reliability ranges from 0 to 1 in providing this overall assessment of a measure's reliability. As shown in Table 8, the three dimensions have high internal consistency, as shown by the Cronbach alpha value, which is higher than 0.80 in all the dimensions; this indicates that we will be able to continue with the data analysis.

Table 8. Validity and Consistency of the Items of the Questionnaire.

\begin{tabular}{cccccc}
\hline Dimensions & Mean & S.D. & Minimum & Maximum & Cronbach Alpha \\
\cline { 2 - 6 } Technology & 5.06 & 0.91 & 1.00 & 6.00 & 0.8763 \\
Governance & 4.43 & 0.96 & 3.00 & 6.00 & 0.8871 \\
Sustainability & 3.74 & 0.98 & 2.00 & 6.00 & 0.8388 \\
\hline \multicolumn{7}{c}{ Author's own elaboration. }
\end{tabular}

The results were compared with the standard values and as they were between 0.70 and 0.95 (all results above 0.80), they can be considered acceptable (Peterson, 1994) [33,34].

3.2.3. Data Analysis of the Dimensions: Technology, Governance, and Sustainability—A Model Proposal

After verifying the reliability of the items, calculations were made with the means and standard deviation among the responses of the participants.

Table 9 studies the different sub-dimensions broken down into technology, governance, and sustainability, which integrate the model proposed for the SMSTEs. 
Table 9. Dimensions and sub-dimensions of the model proposal.

\begin{tabular}{ccccc}
\hline & $\begin{array}{c}\text { Dimensions } \\
\text { Mean }\end{array}$ & S.D. & Minimum & Maximum \\
\hline Technologies & $\mathbf{5 . 0 6}$ & $\mathbf{0 . 9 1}$ & $\mathbf{1 . 0 0}$ & $\mathbf{6 . 0 0}$ \\
Internet of Things & 4.17 & 0.91 & 2.00 & 5.00 \\
Cloud Computing & 5.75 & 0.86 & 3.00 & 6.00 \\
Big Data & 3.75 & 0.96 & 1.00 & 5.00 \\
Artificial Intelligence and Robotics & 5.75 & 0.86 & 3.00 & 6.00 \\
Mobile technologies & 5.88 & 0.98 & 3.00 & 6.00 \\
Governance & 4.43 & $\mathbf{0 . 9 6}$ & $\mathbf{3 . 0 0}$ & $\mathbf{6 . 0 0}$ \\
Strategy & 4.16 & 1.09 & 3.00 & 6.00 \\
Social Responsibility & 4.80 & 0.95 & 3.00 & 5.00 \\
Ethics & 4.65 & 1.04 & 3.00 & 5.00 \\
Legal framework & 4.11 & 0.77 & 3.00 & 6.00 \\
Sustainability & 3.74 & $\mathbf{0 . 9 8}$ & $\mathbf{2 . 0 0}$ & $\mathbf{6 . 0 0}$ \\
Integrated approach & 3.89 & 0.78 & 3.00 & 5.00 \\
Partnerships for sustainability & 3.14 & 0.95 & 2.00 & 6.00 \\
Sustainability monitoring and reporting tools & 4.19 & 1.20 & 3.00 & 6.00 \\
\hline
\end{tabular}

Source: Author's own elaboration.

We observed significant differences between respondents expressed through large values for standard deviations and considerable differences between minimum and maximum values.

The first dimension, "Technologies", suggests the Internet of Things, cloud computing, big data, artificial intelligence and robotics, and mobile technologies. As indicated by Table 8, the respondents' opinion was largely overall in agreement with this position: (a) Mobile technologies: $M=5.88$, $\mathrm{SD}=0.98$; (b) Artificial intelligence and robotics: $\mathrm{M}=5.75, \mathrm{SD}=0.86$; (c) Cloud computing: $\mathrm{M}=5.75$, $\mathrm{SD}=0.86$; (d) Internet of Things: $\mathrm{M}=4.17, \mathrm{SD}=0.91$; (e) Big data: $\mathrm{M}=3.75, \mathrm{SD}=0.96$. The majority of respondents perceived this dimension as the most important for promoting innovation in SMSTEs.

The second dimension, "Governance", suggests the dimensions strategy, social responsibility, ethics, and a legal framework. As indicated by Table 8, the respondents' opinion was largely overall in agreement with this position: (a) Social Responsibility: $\mathrm{M}=4.80, \mathrm{SD}=0.95$; (b) Ethics: $\mathrm{M}=4.65$, $\mathrm{SD}=1.04$; (c) Strategy: $\mathrm{M}=4.16, \mathrm{SD}=1.09$; (d) Legal framework: $\mathrm{M}=4.11, \mathrm{SD}=0.77$. The majority of respondents perceived this dimension as the second most important for promoting innovation in SMSTEs.

The third dimension, "Sustainability," suggests the dimensions of the integrated approach, partnerships for sustainability, and sustainability monitoring and reporting tools. As indicated by Table 9, the respondents' opinion was largely overall in agreement with this position: (a) Sustainability monitoring and reporting tools: $\mathrm{M}=4.19, \mathrm{SD}=1.20$; (b) Integrated approach: $\mathrm{M}=3.89, \mathrm{SD}=0.78$; (c) Partnerships for sustainability: $\mathrm{M}=3.14, \mathrm{SD}=0.95$. The majority of respondents perceived this dimension as the third most important for promoting innovation in SMSTEs.

In general, experts considered that technology was the most important dimension and related with it, mobile technologies, as they are widely used by citizens, and almost all daily life activities can be done with apps (applications using smartphones). Secondly the dimension governance achieved a result that ranked it in second place, being social responsibility the sub-dimension with the highest mean value, as it affects the quality of life of the citizens because the actions or projects in this dominion can be important to improve the community infrastructures and the lifestyles of the citizens. Thirdly, the dimension sustainability with the sub-dimension sustainability monitoring and reporting tools being considered the most important to measure the activities related to the environment, natural resources, mobility, and energy. 


\section{Discussion and Implications of the Research}

\subsection{Discussion of the Model Proposal}

The model proposed is a framework and a tool to evaluate the management capability to implement a business model based on disruptive technologies and includes three dimensions. The first dimension is technology: at this level, managers concentrate on the diverse disruptive technologies that can boost their business and all the techniques they can use to plan, implement, and monitor the process.

The dimension governance consists of managing the internal team efforts in order to achieve predefined business goals with predetermined constraints on time and resources of all kinds, namely, financial, equipment, technology, and other [29].

The dimension sustainability consists of the integration of a set of activities considering a long-term strategy. Sustainable development principles must be integrated into all phases of the model: conceptualization, feasibility, bidding, strategic and operational planning, and operations. At this level, the managerial approach must be more comprehensive and include a balanced view on how to distribute scarce resources between competing desires.

The research hypothesizes that a company located in SMSTEs willing to expand its business when using this model has a higher probability of success. These dimensions can also be the trigger for the next step of SMSTEs, as preparation for becoming a smart city. On the one hand, governance is one of the vectors for managing a city considering ethics and in compliance with the law, promoting the trust of the citizens and their participation at a social, economic, and political level. On the other hand, technology is a vector to improve the competitiveness of SMSTEs, promoting the digital transformation of public services and the industry. The other dimension, sustainability, is also a vector for a smart city, promoting the use of renewable energy and the development of sustainable solutions for the construction and rehabilitation of buildings. This dimension also contributes to climate change and includes intelligent systems of water and waste. Also, the implementation of efficient mobility systems through the use of eco-efficient vehicles and the development of intelligent mobility solutions are all part of the smart city concept. The ultimate goal is using innovation as a strategy to accomplish the needs of citizens and all other stakeholders.

\subsection{Policy Implications}

The study contributes to the political discussion of public policies to be implemented in SMSTEs and can also contribute to the creation of an innovation culture through the identification of the most relevant dimensions regarding technology, governance, and sustainability.

Moreover, policy can promote the investment in technologies as an opportunity to stimulate economic growth in SMSTEs, but, similar to other innovations, it requires the necessary conditions for the realization of its potential: (i) specific support for SMEs; (ii) promotion of trust in technology among citizens and companies; (iii) training and qualification of youth and professionals; (iv) stimulating and supporting research and innovation; (v) definition of ethical rules for its use; (vi) comprehensive data protection; (vii) safeguarding respect for human and human rights in the use of technology; (viii) digital networks of specialists. The policy also needs to create quality standards regarding data to have accurate forecasts, formulate recommendations, and make more accurate and less costly political and managerial decisions with essential productivity gains.

Another critical role of policy is to define regulations regarding principals of ethics and create a framework regarding digital innovation to address societal challenges, particularly concerning European citizens' daily lives (i.e., $4 \mathrm{P}$ medicine, more predictive, preventive, personalized, and participatory mode of healthcare delivery). Also, the transformation of the public services operation reduces bureaucracy and as a mean to transform cities in more smart places for citizens (increasing the energy efficiency, facilitating mobility, and increasing the quality of life). 


\subsection{Managerial Implications}

From a critical point of view, two aspects are worth mentioning regarding this research: (1) the link between technologies, governance, and sustainability was essential from a multidisciplinary approach and (2) to present a practical model that can be applied in practice, namely, the dimensions and sub-dimensions identified in the model proposed. The model proposed can help companies to increase their presence in the market, being more organized and efficient. It also leads to significant participation in innovation networks and in increasing partnerships to access new knowledge and new markets. This research also gives insights about the governance model considering all the stakeholders for companies to achieve better performance and to be more responsible and ethical.

This research also sheds some light on how to achieve sustainability regarding different types of resources, including financial and natural resources. Moreover, it indicates the main vectors of a smart city to shed some light on the possibility of a city becoming a smart city.

\section{Limitations and Future Research}

The research has several limitations: efforts to carry out research that was theoretically and empirically strong had an impact on the findings, as follows: There are few studies with this approach for the SMSTEs, considering the dimensions under analysis. Hence, to develop a framework and cross-validate findings, very little past data were available. Another limitation is the small sample size, and this influences the results, i.e., not possible to generalize. However, the participants in the research are experts on the field, and this can give the research viability and feasibility.

Regarding future research, while this study covered variables that were identified based on the literature, other factors could have been studied as political and economic perspectives, which are essential to identify strategies for SMSTEs' development. Furthermore, a comparison among this study and other studies in other regions will shed light on the results achieved and will complement them. Finally, this study is based on the empirical analysis carried out using a questionnaire, being primarily quantitative. In the future, this can be complemented with in-depth interviews to capture qualitative data and triangulate the results, studying this phenomenon (SMSTEs) in more depth in order to give recommendations for policy and managers.

\section{Conclusions}

This article identifies the leading disruptive technologies that are emerging and their impact on the generation of innovation in SMSTEs.

Technologies create opportunities for innovation, leading to many changes. For example, cloud computing can cause innovation in business models. On the other hand, disruptive technologies have given rise to new ways of doing business, such as the Internet of Things (IoT) solutions, which help integrate business processes.

Companies tend to develop new skills by enhancing their competitive capacity through the adoption of technologies such as the Internet of Things, cloud computing, mobile technologies, artificial intelligence, big data, robotics, and nanotechnology, apart from all the regulations and also the taxes applied to the export of products.

This research proposes a model to boost innovation in SMSTEs based on disruptive technologies; thus, it can drive new digital business models facilitating the trade relations among countries and regions. However, there are also local, national, regional, and international conditions, needing strong governance and the ability to play an active part in promoting measures favouring sustainable development.

In this context, technologies can also provide disruptive opportunities for companies located in SMSTEs that can be identified in the following areas: operational management, predictive and remote maintenance; hardware innovations; increasing the visibility of products, processes, customers, and partners; new related ecosystems, based on software platforms without industry boundaries; 
collaboration between people and machines, which will result in high levels of productivity; there are new opportunities for people to develop their skills and take on new types of jobs which are created; and increasing frequency of "digital work" in the form of intelligent alerts and intelligent robots. The return on investment is the long term and certainly worth the effort for SMSTEs.

Author Contributions: This study was designed and carried out by all of the authors. All of the authors conceived, wrote, and revised the introduction, literature review, the model proposal, discussion, and conclusions. All authors have read and agreed to the published version of the manuscript.

Funding: This research was partially funded by the Plan Andaluz de Investigación, Desarrollo e Innovación, Grupo SEJ-124 (Spain), and by Sustainability.

Acknowledgments: The authors would like to acknowledge the participants in the study and the reviewers.

Conflicts of Interest: The authors declare no conflict of interest.

\section{References}

1. Acemoglu, D.; Autor, D. Under Construction. Skills, Tasks, and Technologies: Implications for Employment and Earnings. In HLE; MIT Press: Cambridge, MA, USA, 2011.

2. Vaz, M.T.N.; Viaene, J.; Wigier, M. (Eds.) Innovation in the Small Firms and Dynamics of Local Development; Scholar: Warsaw, Poland, 2004.

3. Brynjolfsson, E.; McAfee, A.; Cummings, J. The Second Machine Age: Work, Progress, and Prosperity in a Time of Brilliant Technologies; W. W. Norton: New York, NY, USA, 2014.

4. Frey, B.; Osborne, A. The Future of Employment: How Susceptible are Jobs to Computerisation? Academic Publication, Oxford Martin School, University of Oxford: Oxford, UK, 2013.

5. Noronha, T.; Vaz, E.; Nijkamp, P. (Eds.) Small towns of hope and glory. In Small Towns in the Rural World; Routledge: London, UK, 2013.

6. Vaz, E.; De Noronha, T.; Nijkamp, P.; De Noronha, M.T. Exploratory Landscape Metrics for Agricultural Sustainability. Agroecol. Sustain. Food Syst. 2013, 38, 92-108. [CrossRef]

7. De Noronha, T.; Vaz, E. Framing urban habitats: The small and medium towns in the peripheries. Habitat Int. 2015, 45, 147-155. [CrossRef]

8. Chui, M.; Löffler, M.; Roberts, R. The Internet of Things. McKinsey Quarterly 2010, 2, 1-9.

9. Barro, S.; Davenport, T.H. People and machines: Partners in innovation. MIT Sloan Manag. Rev. 2019, 60, 22-28.

10. Maluck, J.; Glanemann, N.; Donner, R.V. Bilateral Trade Agreements and the Interconnectedness of Global Trade. Front. Phys. 2018, 6, 134. [CrossRef]

11. Shultz, G.P. Game Changers: Energy on the Move by Stanford; Hoover Institution Press, Stanford University: Stanford, CA, USA, 2014.

12. Delloite. Industry 4.0 Challenges and Solutions for the Digital Transformation and Use of Exponential Technologies; Delloite: New York, NY, USA, 2014.

13. Berger, R. Industry 4.0-The New Industrial Revolution; Alle Publikationen: Halle (Saale), Germany, 2014.

14. Kobrinskaya, I. Update-Russia and the World, October 2018: The Autumn of Our Discontent? New Perspect. Interdiscip. J. Cent. East Eur. Politics Int. Relat. 2018, 26, 167-174.

15. Böhm, S.; Adam, F.; Farrell, W.C. Impact of the Mobile Operating System on Smartphone Buying Decisions: A Conjoint-Based Empirical Analysis. In Lecture Notes in Computer Science, Proceedings of the MobiWIS 2015: Mobile Web and Intelligent Information Systems, Rome, Italy, 24-26 August 2015; Younas, M., Awan, I., Mecella, M., Eds.; Springer: Cham, Switzerland, 2015; Volume 9228.

16. Betzing, J.H.; Tietz, M.; Brocke, J.V.; Becker, J. The impact of transparency on mobile privacy decision making. Electron. Mark. 2019, 1-19. [CrossRef]

17. Guinard, D.; Trifa, V.; Mattern, F.; Wilde, E. From the Internet of Things to the Web of Things: Resource-oriented Architecture and Best Practices. In Architecting the Internet of Things; Springer Science and Business Media LLC: Berlin/Heidelberg, Germany, 2011; pp. 97-129.

18. Gluhak, A.; Razafindralambo, T.; Krco, S.; Nati, M.; Pfisterer, D.; Mitton, N. A survey on facilities for experimental internet of things research. IEEE Commun. Mag. 2011, 49, 58-67. [CrossRef] 
19. Maló, P. Deliverable D3.1b Roadmaps for IoT Deployments. In Pursuing Roadmaps and BEnchmarks for the Internet of Things; FP7-288315 PROBE-IT; IEEE: Miami, FL, USA, 2013.

20. Porter, M.; Heppelman, J. How Smart, Connected Products are Transforming Competition. Harv. Bus. Rev. 2014, 92, 64-88.

21. World Economic Forum. Industrial Internet of Things: Unleashing the Potential of Connected Products and Services; World Economic Forum: Cologny, Switzerland, 2015.

22. Davenport, T.; Guha, A.; Grewal, D.; Bressgott, T. How artificial intelligence will change the future of marketing. J. Acad. Mark. Sci. 2019, 48, 24-42. [CrossRef]

23. Durnev, A.; Kim, E.H. To Steal or Not to Steal: Firm Attributes, Legal Environment, and Valuation. J. Finance 2005, 60, 1461-1493. [CrossRef]

24. Sethi, S.P. Corporate Codes of Conduct and the Success of Globalization. Ethic Int. Aff. 2002, 16, 89-106. [CrossRef]

25. Becht, M.; Bolton, P.; Roell, A.A. Corporate Governance and Control . In Handbook of the Economics of Finance; Costantinides, G., Harris, M., Stulz, R., Eds.; North-Holland: Amsterdam, The Netherlands, 2003; pp. 1-109.

26. Crowther, D. A Social Critique of Corporate Reporting; Ashgate: Aldershot, UK, 2002.

27. Hawken, P. The Ecology of Commerce: A Declaration of Sustainability; Harper Business: New York, NY, USA, 1993.

28. Aras, G.; Crowther, D. Governance and sustainability. Manag. Decis. 2008, 46, 433-448. [CrossRef]

29. Adami, C. Artificial intelligence: Robots with instincts. Nature 2015, 521, 426-427. [CrossRef] [PubMed]

30. Beaino, G.C.; Lombardi, D.; Siklos, P.L. The Transmission of Financial Shocks on a Global Scale: Some New Empirical Evidence. Emerg. Mark. Financ. Trade 2019, 55, 1634-1655. [CrossRef]

31. European Union. Digital Transformation Scoreboard 2018-EU Business Go Digital: Opportunities, Outcomes, and Uptake; Executive Agency for Small and Medium-sized Enterprises (European Commission): Brussels, Belgium, 2018.

32. Camero, A.; Alba, E. Smart City and information technology: A review. Cities 2019, 93, 84-94. [CrossRef]

33. Kerlinger, N. Foundations of Behavioural Research, 3rd ed.; CBS Publishing: New York, NY, USA, 1986.

34. Peterson, R.A. A Meta-Analysis of Cronbach's Coefficient Alpha. J. Consum. Res. 1994, 21, 381. [CrossRef] 